\title{
Effect of Microstructure on the Compressive Mechanical Properties of Ti-20Zr-6.5Al-4V Alloy
}

\author{
Yuanbiao TAN ${ }^{1}$, Jingli DUAN ${ }^{2}$, Wenchang LIU $^{2}$, Song XIANG ${ }^{1}$, Fei ZHAO ${ }^{1}$, \\ Yilong LIANG ${ }^{1}$
}

${ }^{1}$ Guizhou Key Laboratory of Materials Mechanical Behavior and Microstructure, College of Materials and Metallurgy, Guizhou University, Guiyang 550025, P.R. China

${ }^{2}$ Key Laboratory of Metastable Materials Science and Technology, College of Materials Science and Engineering, Yanshan University, Qinhuangdao 066004, P.R. China

crossref http://dx.doi.org/10.5755/j01.ms.25.1.18737

Received 01 August 2017; accepted 04 February 2018

\begin{abstract}
The effect of microstructure on the mechanical properties of Ti-20Zr-6.5Al-4V alloy after solution and aging treatment was investigated by compression tests. The results showed that the microstructure was consisted of a duplex phase $\alpha^{\prime \prime}+\beta$ structure after solution treatment. With increasing solution treatment temperature, the size of $\beta$ phase grain increased and the amount of $\alpha^{\prime \prime}$ phase decreased. The ultimate compressive strength and elongation decreased with increasing solution treatment temperature, while the yield strength increased. After aging-treatment at $700{ }^{\circ} \mathrm{C}$ for $1.5 \mathrm{~h}$, the microstructure consisted of a large amount of globular $\alpha$ phase, a little amount of fine acicular $\alpha$ phase and bulk $\beta$ phase for the samples solution-treated at $850^{\circ} \mathrm{C}$ for $0.5 \mathrm{~h}$. With increasing initial solution treatment temperature, the amount of globular $\alpha$ phase and bulk $\beta$ phase decreased, however, the amount and size of acicular $\alpha$ phase increased after aging treatment. The ultimate compressive strength and elongation decreased with increasing initial solution treatment temperature, whereas the yield strength firstly increased, and then slightly decreased.

Keywords: Ti alloy, deformation, mechanical properties, microstructure, phase transformation.
\end{abstract}

\section{INTRODUCTION}

Titanium and titanium alloys have been popularly used in aerospace, energy, and chemical processing industries due to the combination of their attractive comprehensive properties, such as exceptional strength-to-weight ratio, excellent weldability, reasonable ductility, ability to withstand high temperature and resistance to corrosion [1-3]. Among titanium alloys, Ti-6Al-4V alloy is the most widely used material because of its excellent strength, low modulus of elasticity, low density, and good corrosion resistance in aerospace industries [4-6]. However, the room temperature ductility of $\mathrm{Ti}-6 \mathrm{Al}-4 \mathrm{~V}$ alloy is generally less than that of the common structural metals including stainless steels [7]. In order to satisfy the room temperature ductility and high strength requirements of Ti-6Al-4V alloy in aircraft applications, it is necessary to improve the mechanical properties of Ti-6Al-4V alloy. The addition of alloying elements is considered to be an important way to improve the mechanical properties of materials $[8,9]$. Elements Zirconium ( $\mathrm{Zr}$ ) and Ti belong to the same group in the element periodic table, which show similar physicochemical properties. $\mathrm{Ti}$ and $\mathrm{Zr}$ have two kinds of crystal structure, namely, high-temperature $\beta$-phase (body centered cubic structure) and low-temperature $\alpha$-phase (hexagonal close-packed structure), and can form an infinitely miscible solid solution. Therefore, the mechanical properties can be improved by the addition of $\mathrm{Zr}$ alloying element. Recently, Jing et al. [10-12]

\footnotetext{
${ }^{*}$ Corresponding author. Tel.: +86 3358074795
}

E-mail address: ybtan1@gzu.edu.cn_(Y.B. Tan) designed new Ti-20Zr-6.5Al-4V alloy by the addition of $\mathrm{Zr}$ element based on Ti-6Al-4V alloy. The alloy with high strength and favorable ductility can be used as advanced structural material.

It is well known that the mechanical properties of materials depend on its initial microstructures. Understanding the relationship between microstructure and mechanical properties are critical for further improving the mechanical properties of the new Ti-20Zr-6.5Al-4V alloy. Jing et al. [11] have reported that the transformation of $\beta$ phase to orthorhombic martensite $\alpha^{\prime \prime}$ phase can occur when Ti-20Zr-6.5Al-4V alloy was solution treated and quenched from the $\beta$ single phase field. The $\alpha^{\prime \prime}$ phase is softer than the disordered $\beta$ phase [13]. However, the microhardness, bending strength and bending modulus of the $\alpha^{\prime \prime}$ phase were higher than that of $\beta$ phase [14]. The $\alpha^{\prime \prime}$ phase also has a pronounced effect on the yield strength. Compressive strength and ductility of the alloy, which result in an improved balance of strength and ductility [15-17]. Aeby Gautier et al. [17] and Bhattacharjee et al. [18] have reported that the $\alpha$ " phase transformation was significantly affected by heat treatment temperature and initial grain size. Low solution temperature or small $\beta$ grain size were all conducive to the transformation of the $\beta$ to $\alpha$ " phase. When Ti-20Zr-6.5Al-4V alloy was solution-treated and quenched from the $\alpha+\beta$ and single $\beta$ phase field at different temperatures, the different $\beta$ phase microstructure with orthorhombic martensite $\alpha$ " phase can be obtained, which has a significantly effect on the mechanical properties of Ti-20Zr-6.5Al-4V alloy. Therefore, in the present work, the alloy was solution and aging-treated at different temperatures to obtain different microstructures. 
An attempt was made to investigate the effect of microstructure on the mechanical properties of $\mathrm{Ti}-20 \mathrm{Zr}$ $6.5 \mathrm{Al}-4 \mathrm{~V}$ alloy after solution and aging treatment to further improve the mechanical properties of the alloy.

\section{EXPERIMENTAL PROCEDURE}

Sponge $\quad \mathrm{Ti} \quad(99.7$ wt.\%), sponge $\mathrm{Zr}$ ( $\mathrm{Zr}+\mathrm{Hf} \geq 99.5 \mathrm{wt} . \%)$, industrially pure $\mathrm{Al}$ (99.5 wt.\%), and $\mathrm{V}(99.9 \mathrm{wt} \%)$ were used to prepare the Ti-20Zr-6.5Al-4V (wt.\%) alloy. The alloy was melted three times using a vacuum consumable electro-arc furnace to ensure a homogeneous chemical composition. The cast ingot was homogenized at $1000{ }^{\circ} \mathrm{C}$ for $12 \mathrm{~h}$, followed by cooling to room temperature, and then multiply forged to completely break the cast structure after being held at $1000{ }^{\circ} \mathrm{C}$ for $1.5 \mathrm{~h}$. The alloy billet was held at $900{ }^{\circ} \mathrm{C}$ for $1.5 \mathrm{~h}$ in the $\alpha+\beta$ phase field and then hot-forged into bars of $40 \mathrm{~mm}$ in diameter. The $\alpha \rightarrow \alpha+\beta$ and $\alpha+\beta \rightarrow \beta$ transformation temperatures of this alloy were determined by differential scanning calorimetry to be $789{ }^{\circ} \mathrm{C}$ and $946{ }^{\circ} \mathrm{C}$, respectively [11].

In order to investigate the effect of microstructure on the mechanical properties of Ti-20Zr-6.5Al-4V alloy after solution and aging treatment, cylindrical compression samples of $9 \mathrm{~mm}$ in height and $6 \mathrm{~mm}$ in diameter were cut from the bars. All samples were solution-treated at $850{ }^{\circ} \mathrm{C}$, $900{ }^{\circ} \mathrm{C}, 950{ }^{\circ} \mathrm{C}$ and $1000^{\circ} \mathrm{C}$ for $0.5 \mathrm{~h}$ in a tubular vacuum heat-treatment furnace with a protective argon atmosphere followed by water quenching, respectively. The aging treatments were performed at $700{ }^{\circ} \mathrm{C}$ for $1.5 \mathrm{~h}$ for the solution-treated samples.

Compression tests were performed on Gleeble 3500 thermo-mechanical simulator at a strain rate of $10^{-3} \mathrm{~s}^{-1}$ at room temperature. For each condition at least 3 samples were deformed, to make sure sufficient accuracy in the relevant results was obtained. The phase component of the samples after solution and aging treatment were determined by D/MAX- 2500/PC X-ray diffractometer (XRD) with $\mathrm{CuK}_{\alpha}$ radiation and a graphite monochromator operated at $40 \mathrm{kV}$ and $200 \mathrm{~mA}$. The X-ray wavelength and scan rate were $1.54 \AA$ and $2 \%$ min, respectively. To observe the microstructure of the samples after solution and aging treatment, the solution and aging-treated samples were mechanically polished and chemically etched using a solution of $5 \%$ hydrofluoric acid (HF), $15 \%$ nitric acid $\left(\mathrm{HNO}_{3}\right)$, and $80 \%$ distilled water $\left(\mathrm{H}_{2} \mathrm{O}\right)$. Microstructural analysis was performed via optical microscopy (OM) and scanning electron microscopy (SEM).

\section{RESULTS AND DISCUSSION}

\subsection{Phase composition after solution and aging treatment}

Fig. 1 shows the XRD patterns of the Ti-20Zr-6.5Al-4V alloy solution-treated at different temperatures for $0.5 \mathrm{~h}$. It is seen that the XRD patterns of the Ti-20Zr-6.5Al-4V alloy showed clear diffraction peaks of $\alpha^{\prime \prime}$ and $\beta$ phase, indicating that the samples consisted of a duplex phase $\alpha^{\prime \prime}+\beta$ microstructure after solution treatment. A similar phenomenon was also observed in others Ti alloys [19-21]. The formation of the $\alpha$ " phase in Ti alloys was associated with the stability elements of the $\beta$ phase $[19,21]$. Some effective laws on the effects of alloying elements on phase stability and martensitic transformation of $\mathrm{Ti}$ and $\mathrm{Ti}$ alloys have been reported in the previous researches. The most widely accepted law is called $\beta$ stabilizer content law, which shows that the martensitic structure of water quenched $\mathrm{Ti}$ and $\mathrm{Ti}$ alloys from $\beta$ temperature zone changes as the order, $\alpha^{\prime} \rightarrow \alpha^{\prime \prime} \rightarrow \omega \rightarrow \beta$ phase, as the increasing of $\beta$ stabilizer content $[22,23]$. In the present work, the zirconium and vanadium elements were involved in Ti-20Zr-6.5Al-4V alloy. The vanadium element is a kind of stability element of $\beta$ phase. The addition of $\mathrm{V}$ element into a $\mathrm{Ti}$ alloy significantly increases the stability of $\beta$ phase, which is helpful to the formation of $\alpha^{\prime \prime}$ phase during quenching. Moreover, When the $\mathrm{Zr}$ element is added to $\mathrm{Ti}$ alloys, $\mathrm{Zr}$ and Ti can form an infinitely miscible solid solution. The interaction and influence of $\mathrm{Zr}$ on $\mathrm{Ti}$ alloys or of $\mathrm{Ti}$ on $\mathrm{Zr}$ alloys can result in a change in the phase stability of $\mathrm{Ti}$ alloys [19, 24-26]. Liang et al. [19] showed that the $\beta$ phase stability of $\mathrm{Ti}$ alloys increased with increasing $\mathrm{Zr}$ element when the content of $\mathrm{Zr}$ element is less than $30 \%$ in Ti alloys, which is also beneficial for the formation of $\alpha^{\prime \prime}$ phase during quenching. With decreasing solution treatment temperature from 1000 to $850{ }^{\circ} \mathrm{C}$, the amount of $\alpha^{\prime \prime}$ phase gradually increased. This is attributed to a decrease in initial $\beta$ grain size with decreasing solution treatment temperature.

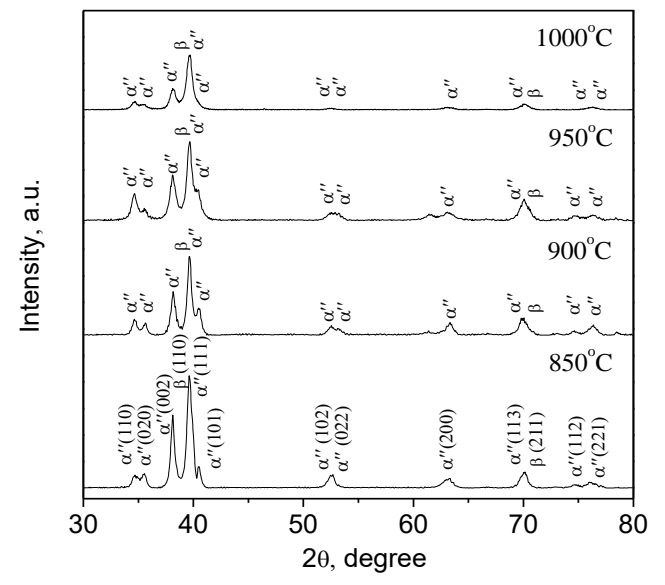

Fig. 1. XRD patterns of the Ti-20Zr-6.5Al-4V alloy solutiontreated at different temperatures for $0.5 \mathrm{~h}$

Small $\beta$ grain size showed an increase in number of grain boundaries compared to large $\beta$ grain size. Grain boundary with high energy is much more disordered than in the interior of the grains, which promotes the nucleation of the $\alpha$ " phase.

Fig. 2 a shows The XRD patterns of the solutiontreated $\mathrm{Ti}-20 \mathrm{Zr}-6.5 \mathrm{Al}-4 \mathrm{~V}$ alloy after aging-treatment at $700{ }^{\circ} \mathrm{C}$ for $1.5 \mathrm{~h}$. The prominent diffraction peaks of $\alpha$ and weak diffraction peaks of $\beta$ phase were observed in the XRD patterns, while the diffraction peaks of $\alpha^{\prime \prime}$ phase disappeared. This shows that after aging-treated at $700{ }^{\circ} \mathrm{C}$ for $1.5 \mathrm{~h}$, the sample was composed of a large amount of $\alpha$ phase and a small quantity of $\beta$ phase for the solutiontreated samples. In order to quantitatively analyze the 
variation in the volume fraction of $\beta$ phase of the alloy after aging treatment with initial solution treatment temperature, the volume fraction of $\beta$ phase $f_{\beta}$ in the alloy has been calculated using the direct comparison method by XRD [27]:

$$
f_{\beta}=\frac{1}{1+\frac{1}{m} \sum_{i=1}^{m}\left(\frac{I_{i}^{\alpha}}{R_{i}^{\alpha}}\right) / \frac{1}{n} \sum_{i=1}^{n}\left(\frac{I_{i}^{\beta}}{R_{i}^{\beta}}\right)},
$$

where $m$ and $n$ represent the number of diffraction peaks of $\alpha$ and $\beta$ phases used in calculation, respectively. $I$ is the integrated intensity for a diffraction peak corresponding to $\beta$ or $\alpha$ phase. $R$ is the material scattering factor and given by the equation:

$$
R_{i}=\left(\frac{1}{V^{2}}\right)\left[\left|F_{i}\right|^{2} P_{i}\left(\frac{1+\cos ^{2} 2 \theta}{\sin ^{2} \theta \cos \theta}\right)\right]\left(e^{-2 M}\right),
$$

where $V$ is the volume of the unit cell. $F$ is the structure factor and $e^{-2 M}$ is the temperature factor.

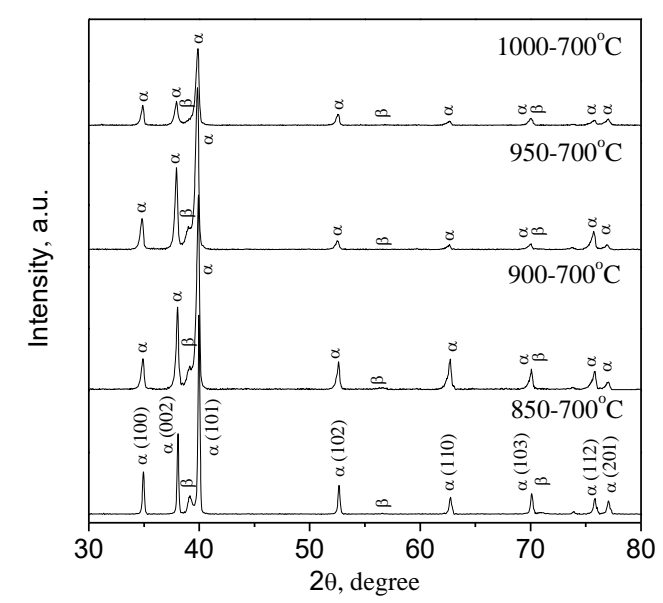

a

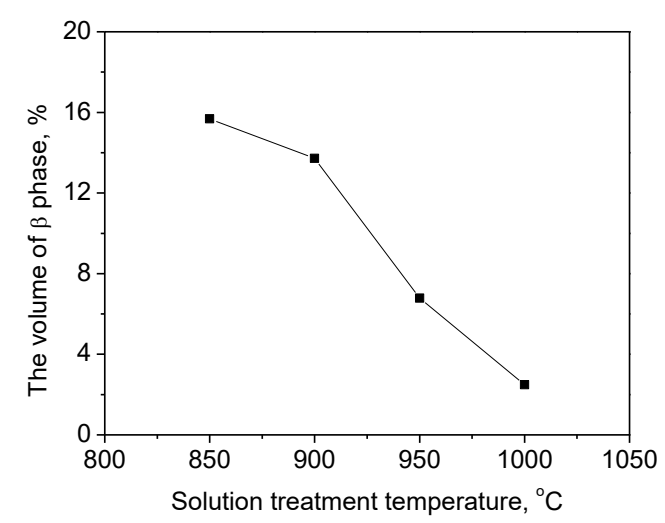

$\mathrm{b}$

Fig. 2. a-XRD patterns of the Ti-20Zr-6.5Al-4V alloy solutiontreated at different temperatures for $0.5 \mathrm{~h}$, and then agingtreated at $700{ }^{\circ} \mathrm{C}$ for $1.5 \mathrm{~h} ; \mathrm{b}$-the variation in the volume fraction of $\beta$ phase of the alloy after aging treatment with initial solution treatment temperature in XRD patterns shown in Fig. 2 a
In this study, the (110) and (200) diffraction peaks of $\beta$ phase as well as the $(10 \overline{1} 0),(0002),(10 \overline{1} 1),(10 \overline{1} 2)$ and

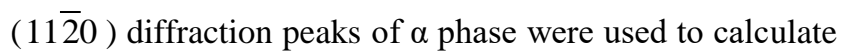
the phase composition.

Fig. $2 \mathrm{~b}$ shows the variation in the volume fraction of the $\beta$ phase of the alloy after aging treatment with initial solution treatment temperature. It is seen from Fig. $2 \mathrm{~b}$ that the amount of remained $\beta$ phase gradually decreased after aging treatment with increasing initial solution treatment temperature from 850 to $1000{ }^{\circ} \mathrm{C}$. This may be associated with the amount of $\alpha^{\prime \prime}$ phase existed in alloy before aging treatment. This is because that the reverse transformation of the $\alpha^{\prime \prime}$ to $\beta$ phase occurred prior to the transformation of the $\beta$ to $\alpha$ phase during aging treatment $[28,29]$, which results in a decrease the remained $\beta$ phase with increasing initial solution treatment temperature during aging treatment.

\subsection{Microstructure after solution and aging treatment}

Fig. 3 shows the optical microstructure on the Ti-20Zr-6.5Al-4V alloy solution treated at various temperatures recorded by optical microscope. It can be seen from Fig. 3 a that the high volume fraction of $\alpha^{\prime \prime}$ phase was observed in the $\beta$ matrix when the samples were solution-treated at $850^{\circ} \mathrm{C}$. This was ascribed to fine $\beta$ phase grain, which promoted the precipitation of $\alpha^{\prime \prime}$ phase during quenching [15]. With increasing solution treatment temperature, the grain size of $\beta$ phase gradually increased and the amount and size of needle-like $\alpha^{\prime \prime}$ phase gradually decreased (Fig. $3 \mathrm{~b}$ to $\mathrm{d}$ ), indicating that large $\beta$ grain easily restrains the growth of the $\alpha^{\prime \prime}$ phase.

Fig. 4 shows the SEM microstructure of the solutiontreated Ti-20Zr-6.5Al-4V alloy aging-treated at $700{ }^{\circ} \mathrm{C}$ for $1.5 \mathrm{~h}$. It is seen from Fig. $4 \mathrm{a}$ that a large amount of globular $\alpha$ phase, a little amount of fine acicular $\alpha$ phase and bulk $\beta$ phase were observed after aging-treatment at $700{ }^{\circ} \mathrm{C}$ and $1.5 \mathrm{~h}$ for the samples solution-treated at $850{ }^{\circ} \mathrm{C}$ for $0.5 \mathrm{~h}$. With increasing initial solution treatment temperature, the amount of globular $\alpha$ phase gradually decreased and the bulk $\beta$ phase was invisible, while the size in length and width and amount of acicular $\alpha$ phase increased (Fig. $4 \mathrm{~b}$ to c). For the samples solution-treated at $1000{ }^{\circ} \mathrm{C}$, the microstructure was mainly composed primarily of acicular $\alpha$ phase after aging-treated at $700{ }^{\circ} \mathrm{C}$ for $1.5 \mathrm{~h}$ (Fig. $4 \mathrm{~d}$ ), which is associated with the solution treatment temperature. $\mathrm{Ti}$ alloy undergone solution treatment, quenching and aging treatment may produce a microstructure consisting of globular and/or acicular $\alpha$ phase in $\beta$ matrix, which depend on whether the solution treatment has been carried out below or above the $\beta$ transus temperature. When the solution treatment temperature is above the $\beta$ transus temperature, a microstructure was composed mainly of a large amount of acicular $\alpha$ phase. While a microstructure consisting mainly of globular $\alpha$ phase was obtained in $\beta$ matrix at below the $\beta$ transus temperature [30]. In this present work, the solution treatment temperature of $1000{ }^{\circ} \mathrm{C}$ was above the $\beta$ transus temperature. Thus, the microstructure of the alloy was mainly composed of acicular $\alpha$ phase in $\beta$ matrix. 


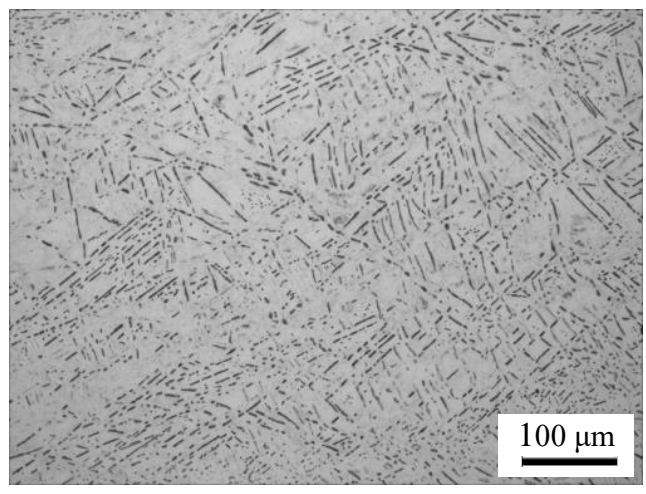

a

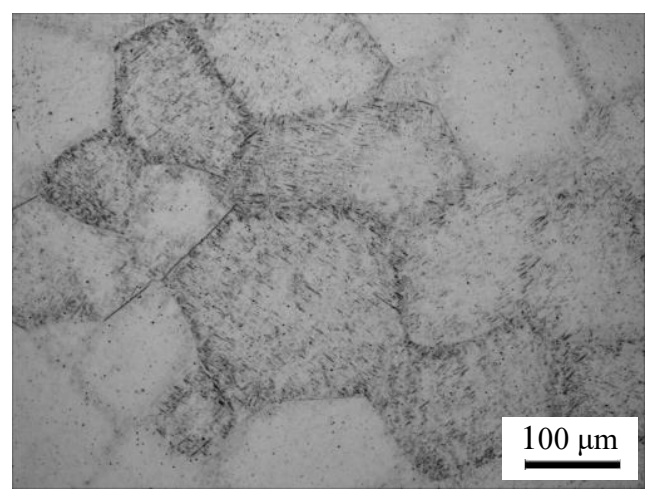

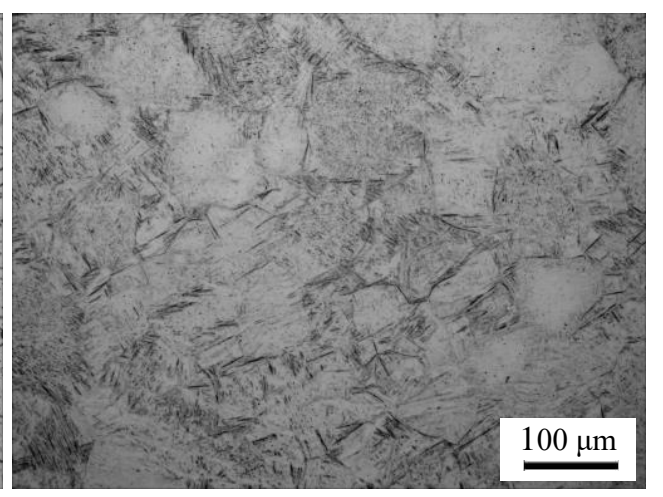

b

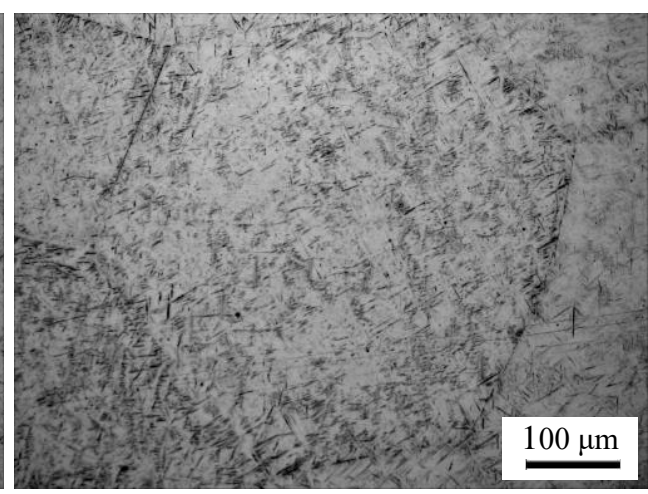

d

Fig. 3. Optical microstructure of the Ti-20Zr-6.5Al-4V alloy after solution treatment at: $\mathrm{a}-850{ }^{\circ} \mathrm{C} ; \mathrm{b}-900{ }^{\circ} \mathrm{C} ; \mathrm{c}-950{ }^{\circ} \mathrm{C} ; \mathrm{d}-1000{ }^{\circ} \mathrm{C}$ for $0.5 \mathrm{~h}$

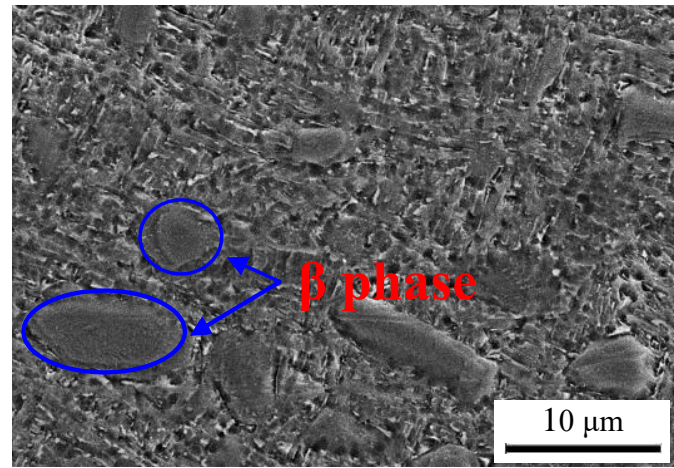

a

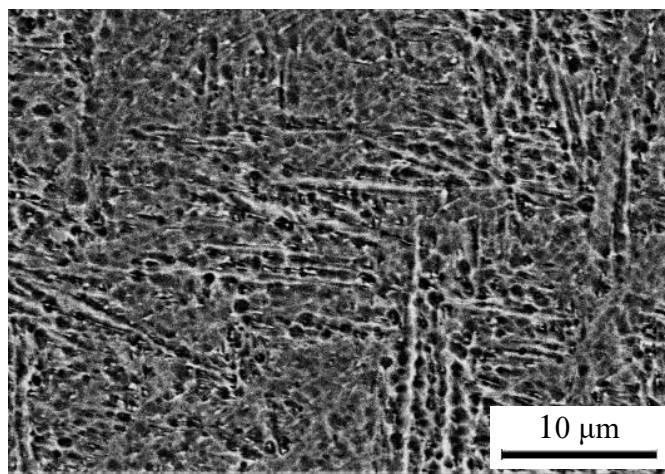

c

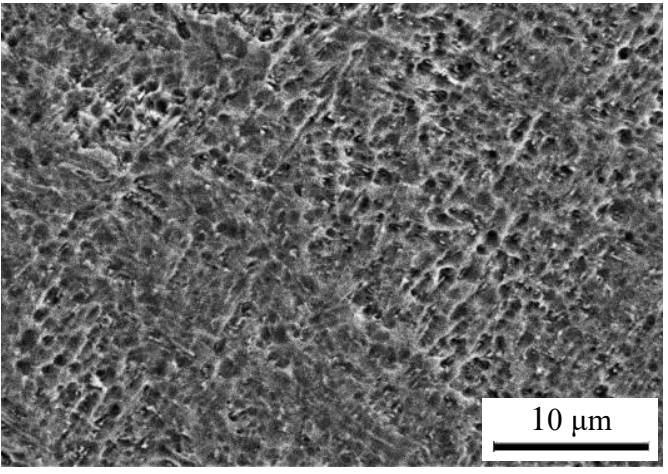

$\mathrm{b}$

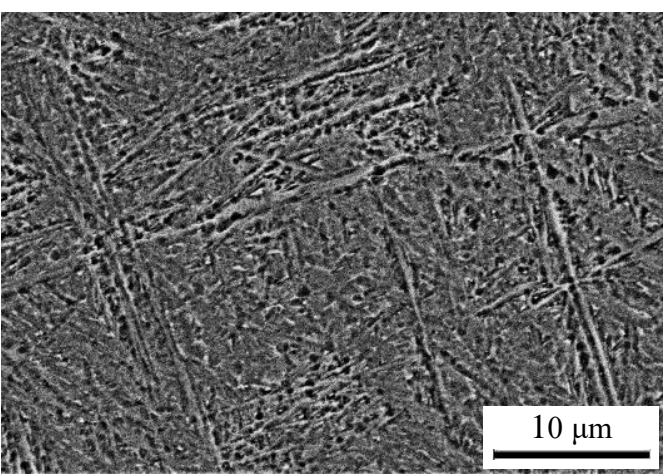

d

Fig. 4. SEM microstructure of the Ti-20Zr-6.5Al-4V alloy after solution treatment at: $\mathrm{a}-850{ }^{\circ} \mathrm{C} ; \mathrm{b}-900{ }^{\circ} \mathrm{C} ; \mathrm{c}-950{ }^{\circ} \mathrm{C} ; \mathrm{d}-1050{ }^{\circ} \mathrm{C}$ for $0.5 \mathrm{~h}$, and then aging treatment at $700{ }^{\circ} \mathrm{C}$ for $1.5 \mathrm{~h}$ 


\subsection{Compressive mechanical properties after solution and aging treatment}

The compressive mechanical properties of the Ti-20Zr-6.5Al-4V alloy are evaluated on the Gleeble 3500 thermo-mechanical simulator. Fig. 5 exhibits true stressstrain curves of the Ti-20Zr-6.5Al-4V alloy at room temperature after solution and aging treatment. The compressive mechanical properties were summarized in Table 1 and Table 2. It is seen from Table 1 that the yield strength $\left(\sigma_{0.2}\right)$, ultimate compressive strength $\left(\sigma_{\mathrm{b}}\right)$, and elongation are $437 \mathrm{MPa}, 1340 \mathrm{MPa}$ and $27.1 \%$ for the samples solution-treated at $850{ }^{\circ} \mathrm{C}$, respectively. It is interesting to note that the stress-strain curves exhibit a low yield strength and excellent ductility for the samples solution-treated at $850^{\circ} \mathrm{C}$ for $0.5 \mathrm{~h}$, as shown in Fig. 5 a. This is associated with the precipitation of the $\alpha^{\prime \prime}$ phase after solution treatment [31-35]. The $\alpha^{\prime \prime}$ phase was softer than the $\beta$ phase, resulting in a low yield strength and excellent ductility $[33,35]$. With increasing solution treatment temperature, the ultimate compressive strength and elongation decreased, while the yield strength slowly increased (Fig. 6 a). When the solution treatment temperature increased to $1000^{\circ} \mathrm{C}$, the ultimate compressive

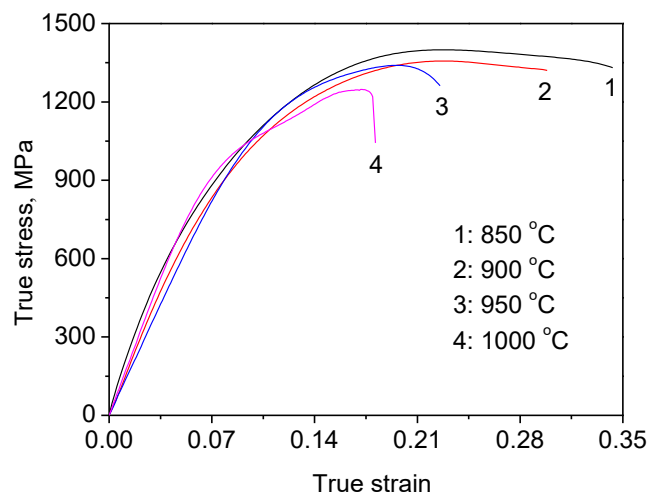

strength and elongation of the solution-treated samples decreased to $1248 \mathrm{MPa}$ and $11.3 \%$, respectively, while the yield strength increased to $687 \mathrm{MPa}$, as shown in Table 1 . This is attributed to a decrease in the amount of $\alpha^{\prime \prime}$ phase and an increase in the grain size of $\beta$ phase with increasing solution treatment temperature. Fig. 5 b shows true stressstrain curves of the solution-treated samples aging-treated at $700{ }^{\circ} \mathrm{C}$ for $1.5 \mathrm{~h}$. It is seen that when the solution-treated alloy was subjected to aging, the yield strength $\left(\sigma_{0.2}\right)$ and ultimate compressive strength $\left(\sigma_{\mathrm{b}}\right)$ significantly increased, while the elongation obviously decreased compared with that of the solution-treated samples. This is mainly associated with the decomposition of $\alpha^{\prime \prime}$ phase and the precipitation of $\alpha$ phase during aging treatment. After aging-treatment at $700{ }^{\circ} \mathrm{C}$ for $1.5 \mathrm{~h}$, It is seen from Table 2 that the yield strength, ultimate compressive strength and elongation of the samples are $1234 \mathrm{MPa}, 1417 \mathrm{MPa}$ and $25.4 \%$ for the samples solution-treated at $850{ }^{\circ} \mathrm{C}$ for $0.5 \mathrm{~h}$, respectively. With increasing initial solution treatment temperature, the ultimate compressive strength and elongation pronouncedly decreased, as shown in Fig. 6 b. This is mainly associated with a decrease in the content of $\beta$ phase and the increase in the size of $\alpha$ phase during aging treatment.

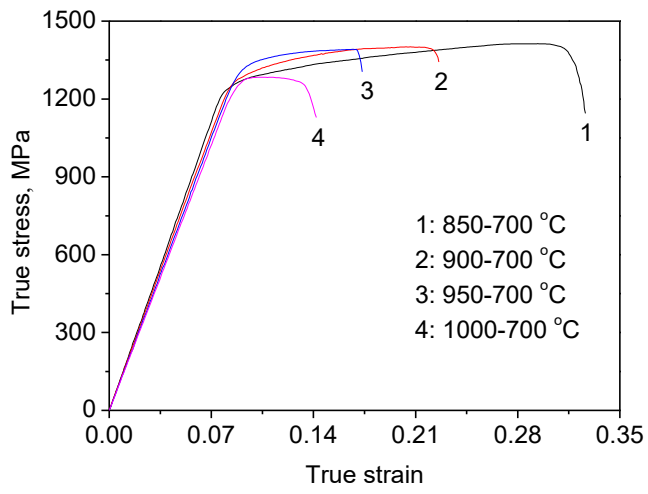

b

Fig. 5. a-compressive stress-strain curves for the Ti-20Zr-6.5Al-4V alloy solution-treated at different temperatures for $0.5 \mathrm{~h}$; $\mathrm{b}$-compressive properties of the Ti-20Zr-6.5Al-4V alloy solution-treated at different temperatures and then aging treated at $700{ }^{\circ} \mathrm{C}$

Table 1. Compressive properties of the Ti-20Zr-6.5Al-4V alloy after solution treatment.

\begin{tabular}{|c|c|c|c|}
\hline Solution treatment temperature, ${ }^{\circ} \mathrm{C}$ & True yield strength, $\mathrm{MPa}$ & True ultimate compressive strength, MPa & Elongation, $\%$ \\
\hline 850 & 437 & 1340 & 27.1 \\
\hline 900 & 557 & 1357 & 20.3 \\
\hline 950 & 669 & 1340 & 12.4 \\
\hline 1000 & 687 & 1248 & 11.3 \\
\hline
\end{tabular}

Table 2. Compressive properties of the Ti-20Zr-6.5Al-4V alloy solution-treated at different temperatures and then aging treated at $700^{\circ} \mathrm{C}$

\begin{tabular}{|c|c|c|c|c|}
\hline $\begin{array}{c}\text { Solution treatment } \\
\text { temperature, }{ }^{\circ} \mathrm{C}\end{array}$ & $\begin{array}{c}\text { Aging treatment } \\
\text { temperature, }{ }^{\circ} \mathrm{C}\end{array}$ & True yield strength, MPa & $\begin{array}{c}\text { True ultimate compressive } \\
\text { strength, MPa }\end{array}$ & Elongation, $\%$ \\
\hline 850 & 700 & 1234 & 1417 & 25.4 \\
\hline 900 & 700 & 1241 & 1401 & 14.0 \\
\hline 950 & 700 & 1288 & 1391 & 8.6 \\
\hline 1000 & 700 & 1250 & 1285 & 6.4 \\
\hline
\end{tabular}




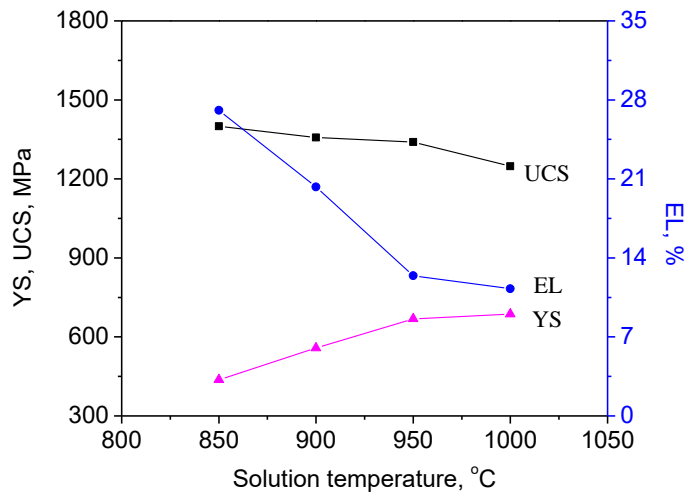

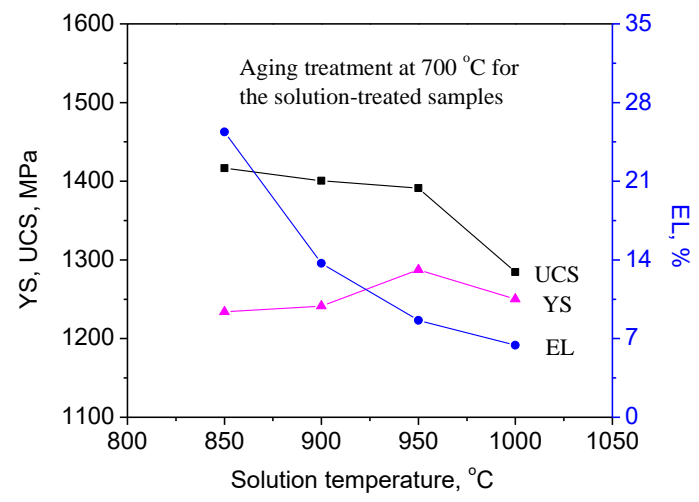

b

Fig. 6. $\mathrm{a}$-the variation in the compressive properties with solution temperature for the Ti-20Zr-6.5Al-4V alloy solution-treated at different temperatures for $0.5 \mathrm{~h} ; \mathrm{b}$-the variation in the compressive properties with solution temperature for the Ti-20Zr-6.5Al-4V alloy solution-treated at different temperatures and then aging-treated at $700{ }^{\circ} \mathrm{C}$ for $1.5 \mathrm{~h}$

As can be seen from Fig. 3 a, the microstructure of the samples consisted of a large amount of globular $\alpha$ phase, a little amount of fine acicular $\alpha$ phase and bulk $\beta$ phase, which resulted in a high ultimate compressive strength and good ductility. With increasing initial solution treatment temperature, the content of globular $\alpha$ phase and $\beta$ phase decreased and the size of acicular $\alpha$ phase in length and width increased, leading to a low ultimate compressive strength and poor ductility. This trend agrees with the HallPetch relationship, i.e. the strength of the material is inversely proportional to the square root of the grain size $[36,37]$. It is note that the yield strength of the alloy after aging-treatment firstly increased with increasing initial solution treatment temperature from 850 to $950{ }^{\circ} \mathrm{C}$ (Fig. 6 b). This may be attributed to an increase in the amount of acicular $\alpha$ phase and a decrease in the amount of globular $\alpha$ phase. Jing et al [12] also reported that the acicular $\alpha$ phase can result in a high yield strength. With increasing initial solution treatment temperature from 950 to $1000{ }^{\circ} \mathrm{C}$, the yield strength of the alloy after agingtreatment slightly decreased. This may be associated with increasing the size in length and width of acicular $\alpha$ phase.

\section{CONCLUSIONS}

The effect of microstructure on the mechanical properties of $\mathrm{Ti}-20 \mathrm{Zr}-6.5 \mathrm{Al}-4 \mathrm{~V}$ alloy after solution and aging treatment was investigated. The main conclusions are as follows:

1. After solution treatment, all samples consisted of $\alpha^{\prime \prime}+\beta$ duplex phase. With increasing solution treatment temperature, the grain size of $\beta$ phase gradually increased and the amount of $\alpha^{\prime \prime}$ phase decreased.

2. After aging-treatment at $700{ }^{\circ} \mathrm{C}$, the microstructure was consisted of a large amount of globular $\alpha$ phase, a little amount of fine acicular $\alpha$ phase and bulk $\beta$ phase for the samples solution-treated at $850^{\circ} \mathrm{C}$. With increasing initial solution treatment temperature, the amount of globular $\alpha$ phase and bulk $\beta$ phase decreased, while the amount and size of acicular $\alpha$ phase increased.
3. For the solution-treated Ti-20Zr-6.5Al-4V alloy, with increasing solution treatment temperature, the ultimate compressive strength and elongation of the alloy decreased, while yield strength increased.

4. After aging-treatment at $700{ }^{\circ} \mathrm{C}$, with increasing initial solution treatment temperature, the ultimate compressive strength and elongation of the alloy decreased, while the yield strength firstly increased, and then slightly decreased.

\section{Acknowledgments}

This work was supported by the Scientific Research Foundation for Introduced Talent of Guizhou University (Grant no. 201629), the National Natural Science Foundation of China (Grant no. 51661006 and 51774103) and the Science and Technology granted by Guizhou Province for financial support (Grant No. 20146013).

\section{REFERENCES}

1. Eylon, D., $\quad$ Vassel, A., $\quad$ Combres, Y., Boyer, R.R., Bania, P.J., Schutz, R.W. Issues in the Development of Beta Titanium Alloys JOM 46 1994: pp. 14-15. https://doi.org/10.1007/BF03220741

2. Ivasishin, O.M., Markovsky, P.E., Matviychuk, Y.V., Semiatin, S.L. Precipitation and Recrystallization Behaviour of Beta Titanium Alloys During Continuous Heat Treatment Metallurgical and Materials Transactions A 34 (1) 2003: pp. $147-158$. https://doi.org/10.1007/s11661-003-0216-8

3. Huang, Z.W. Thermal Stability of Ti-44Al-4Nb-4Zr-0.2Si1B Alloy Intermetallics 42 2013: pp. 170-179. https://doi.org/10.1016/j.intermet.2013.06.007

4. Katou, M., Oh, J., Miyamoto, Y., Matsuura, K., Kudoh, M. Freeform Fabrication of Titanium Metal and Intermetallic Alloys by Three-Dimensional Micro Welding Materials and Design 28 2007: pp. 2093-2098. https://doi.org/10.1016/j.matdes.2006.05.024

5. Charles, C., Jävstrat, N. Development of a Microstructure Model for Metal Deposition of Titanium Alloy Ti-6Al-4V In: 11th World Conference on Titanium (Ti-2007), Kyoto, Japan, 2007.

6. Charles, C., Jävstrat, N. Modelling Ti-6Al-4V Microstructure by Evolution Laws Implemented as Finite 
Element Subroutines: Application to TIG Metal Deposition. In: 8th International Conference on Trends in Welding Research. Pine Mountain, GA, USA, 2008.

7. Beal, J.D., Boyer, R., Sanders, D. Forming of Titanium and Titanium Alloys ASM Handbook. 14B: Metalworking: Sheet Forming, 2006.

8. Lin, D.J., Lin, J.H.C., Ju, C.P. Structure and Properties of Ti-7.5Mo-xFe Alloys Biomaterials 23 2002: pp. $1723-1730$. https://doi.org/10.1016/S0142-9612(01)00233-2

9. Hao, Y.L., Li, S.J., Sun, S.Y., Yang, R. Effect of $\mathrm{Zr}$ and $\mathrm{Sn}$ on Young's Modulus and Superelasticity of Ti-Nb-based Alloys Materials Science and Engineering A 441 2006: pp. $112-118$.

https://doi.org/10.1016/j.msea.2006.09.051

10. Jing, R., Liang, S.X., Liu, C.Y., Ma, M.Z., Zhang, X.Y., Liu, R.P. Structure and Mechanical Properties of Ti-6Al-4V Alloy after Zirconium Addition Materials Science and Engineering A 552 2012: pp. 295-300. https://doi.org/10.1016/j.msea.2012.05.043

11. Jing, R., Liang, S.X., Liu, C.Y., Ma, M.Z., Liu, R.P. Aging Effects on the Microstructures and Mechanical Properties of the Ti-20Zr-6.5Al-4V Alloy Materials Science and Engineering A 559 2013: pp. 474-479. https://doi.org/10.1016/j.msea.2012.08.128

12. Jing, R., Liang, S.X., Liu, C.Y., Ma, M.Z., Liu, R.P. Effect of the Annealing Temperature on the Microstructural Evolution and Mechanical Properties of TiZrAlV Alloy Materials and Design 52 2013: pp. 981-986.

https://doi.org/10.1016/j.matdes.2013.06.039

13. Young, M., Levine, E., Margolin, H. The Aging Martensite Behavior of Orthorhombic in Ti-6-2-4-6 Metallurgical and Materials Transactions B 5 1974: pp. 1891-1898. https://doi.org/10.1007/BF02644157

14. Lee, C.M., Ju, C.P., Lin, J.H.C. Structure-property Relationship of Cast $\mathrm{Ti}-\mathrm{Nb}$ Alloys Journal of Oral rehabilitation 29 2002: pp. 314-322. https://doi.org/10.1046/j.1365-2842.2002.00825.x

15. Li, C., Chen, J.H., Wu, X., van der Zwaag, S. Effect of Strain Rate on Stress-induced Martensitic Formation and the Compressive Properties of $\mathrm{Ti}-\mathrm{V}-(\mathrm{Cr}, \mathrm{Fe})-\mathrm{Al}$ Alloys Materials Science and Engineering A 573 2013: pp. $111-118$. https://doi.org/10.1016/j.msea.2013.03.002

16. Wang, X.D., $\quad$ Lou, H.B., $\quad$ Ståhl, K., $\quad$ Bednarcik, J., Franz, H., Jiang, J.Z. Tensile Behavior of Orthorhombic $\alpha^{\prime \prime}$-titanium Alloy Studied by in situ X-ray Diffraction Materials Science and Engineering A 527 2010: pp. 6596-6600. https://doi.org/10.1016/j.msea.2010.06.065

17. Aeby-Gautier, E., Settefrati, A., Bruneseaux, F., Appolaire, B., Denand, B., Dehmas, M., Geandier, G., Boulet, P. Isothermal $\alpha^{\prime \prime}$ Formation in $\beta$ Metastable Titanium Alloys Journal of Alloys and Compounds 577 2012: pp. 439-443. https://doi.org/10.1016/j.jallcom.2012.02.046

18. Bhattacharjee, A., Bhargava, S., $\quad$ Varma, V.K., Kamat, S.V., Gogia, A.K. Effect of $\beta$ Grain Size on Stress Induced Martensitic Transformation in b Solution Treated Ti-10V-2Fe-3Al Alloy Scripta Materialia 53 2005: pp. 195-200.

https://doi.org/10.1007/s11661-006-0087-x

19. Liang, S.X., Yin, L.X., Zhou, Y.K., Feng, X.J., Ma, M.Z., Liu, R.P., Tan, C.L. Abnormal Martensitic Transformation of High Zr-containing Ti Alloys Journal of Alloys and Compounds 615 2014: pp. 804-808.

https://doi.org/10.1016/j.jallcom.2014.07.041

20. Wu, S.Q., Ping, D.H., Yamabe-Mitarai, Y., Kitashima, T., Li, G.P., Yang, R. Microstructural Characterization on Martensitic $\alpha^{\prime \prime}$ Phase in Ti-Nb-Pd Alloys Journal of Alloys and Compounds 577 2012: pp. S423-S426. https://doi.org/10.1016/j.jallcom.2011.12.152

21. Ho, W.F., Ju, C.P., Lin, J.H.C. Structure and Properties of Cast Binary Ti-Mo Alloys Biomaterials 20 1999: pp. $2115-2122$. https://doi.org/10.1016/S0142-9612(99)00114-3

22. Syarif, J., Rohmannudin, T.N., Omar, M.Z., Sajuri, Z., Harjanto, S. Stability of the Beta Phase in Ti-Mo-Cr Alloy Fabricated by Powder Metallurgy Journal of Mining and Metallurgy Section B Metallurgy 49 2013: pp. 285-292. https://doi.org/10.2298/JMMB121024030S

23. Ma, L.W., Cheng, H.S., Chung, C.Y., Yuan, B. Super Elastic Behavior and Microstructure of Ti19Nb9Zr1Mo (at. \%) Alloy Materials Letters 109 2013: pp. 172-174. https://doi.org/10.1016/j.matlet.2013.07.083

24. Kawakita, M., Takahashi, M., Takahashi, S., YamabeMitarai, Y. Effect of Zr on Phase Transformation and Hightemperature Shape Memory Effect in TiPd Alloys Materials Letters 89 2012: pp. 336-338. https://doi.org/10.1016/j.matlet.2012.07.104

25. Ho, W.F., Chen, W.K., Wu, S.C., Hsu, H.C. Structure, Mechanical Properties, and Grindability of Dental Ti-Zr Alloys Journal of Materials Science: Materials in Medicine 19 2008: pp. 3179-3186. https://doi.org/10.1007/s10856-008-3454-x

26. Zhang, J.Y., Sun, F., Hao, Y.L., Gozdecki, N., Lebrun, E., Vermaut, P., Portier, R., Gloriant, T., Laheurte, P., Prima, F. Influence of Equiatomic $\mathrm{Zr} / \mathrm{Nb}$ Substitution on Superelastic Behavior of Ti-Nb-Zr Alloy Materials Science and Engineering A 563 2013: pp. $78-85$. https://doi.org/10.1016/j.msea.2012.11.045

27. De, A.K., Murdock, D.C., Mataya, M.C., Speer, J.G., Matlock, D.K. Quantitative Measurement of DeformationInduced Martensite in 304 Stainless Steel by X-ray Diffraction Scripta Materials 50 2004: pp. 1445-1449. https://doi.org/10.1016/j.scriptamat.2004.03.011

28. Mantani, Y., Tajima, M. Phase Transformation of Quenched $\alpha^{\prime \prime}$ Martensite by Aging in Ti-Nb Alloys Materials Science and Engineering A 438-440 2006: pp. $315-319$. https://doi.org/10.1016/j.msea.2006.02.180

29. Lin, C., Yin, G.L., Zhao, Y.Q., Ge, P., Liu, Z.L. Analysis of the Effect of Alloy Elements on Martensitic Transformation in Titanium Alloy with the Use of Valence Electron Structure Parameters Materials Chemistry and Physics 125 2011: pp. 411-417. https://doi.org/10.1016/j.matchemphys.2010.10.039

30. Shekhar, S., Sarkar, R., Kar, S.K. Bhattacharjee, A. Effect of Solution Treatment and Aging on Microstructure and Tensile Properties of High Strength $\beta$ Titanium Alloy, Ti-5Al-5V-5Mo-3Cr Materials and Design 66 2015: pp. 596-610. https://doi.org/10.1016/j.matdes.2014.04.015

31. Tang, B., Tang, B., Han, F.B., Yang, G.J., Li, J.S. Influence of Strain Rate on Stress Induced Martensitic Transformation in $\beta$ Solution Treated TB8 Alloy Journal of Alloys and Compounds 565 2013: pp. 1-5. 
https://doi.org/10.1016/j.jallcom.2013.02.173

32. Matlakhova, L.A., Matlakhov, A.N., Monteiro, S.N. Temperature Effect on the Elastic Modulus, Internal Friction and Related Phase Transformations in Ti-Nb-2\%Al Quenched Alloys Materials Characterization 59 2008: pp. $1234-1240$. https://doi.org/10.1016/j.matchar.2007.10.004

33. Yu, Z.T., Zhou, L. Influence of Martensitic Transformation on Mechanical Compatibility of Biomedical $\beta$ Type Titanium Alloy TLM Materials Science and Engineering A 438-440 2006: pp. 391-394.

https://doi.org/10.1016/j.msea.2005.12.079

34. Premkumar, M., Singh, A.K. Deformation Behavior of an Ordered B2 Phase in Ti-25Al-25Zr Alloy Intermetallics 18 2010: pp. 199-201.

https://doi.org/10.1016/j.intermet.2009.07.015
35. Jiang, X.J., Jing, R., Ma, M.Z., Liu, R.P. The Orthorhombic $\alpha^{\prime \prime}$ Martensite Transformation during Water Quenching and its Influence on Mechanical Properties of Ti41Zr-7.3Al Alloy Intermetallics 52 2014: pp. 32-35. https://doi.org/10.1016/j.intermet.2014.03.010

36. Málek, J., Hnilica, F., Veselý, J., Smola, B., Bartáková, S., Vaněk, J. Microstructure and Mechanical Properties of Ti-35Nb-6Ta Alloy after Thermomechanical Treatment Materials Characterization 66 2012: pp. $75-82$.

https://doi.org/10.1016/j.matchar.2012.02.012

37. Emura, S., Araoka, A., Hagiwara, M. B2 grain Size Refinement and its Effect on Room Temperature Tensile Properties of a Ti-22Al-27Nb Orthorhombic Intermetallic Alloy Scripta Materials 48 (5) 2003: pp. 629-634. https://doi.org/10.1016/S1359-6462(02)00462-1 